\title{
Functional outcomes at 2 years of age following treatment for posthemorrhagic hydrocephalus of prematurity: what do we know at the time of consult?
}

\author{
Samuel G. McClugage III, MD, ${ }^{1}$ Nicholas M. B. Laskay, MD, ${ }^{1}$ Brian N. Donahue, MD, ${ }^{2}$ \\ Anastasia Arynchyna, MPH, ${ }^{1}$ Kathrin Zimmerman, BA, ${ }^{1}$ Inmaculada B. Aban, PhD, ${ }^{3}$ \\ Elizabeth N. Alford, MD, ${ }^{1}$ Myriam Peralta-Carcelen, MD, ${ }^{4}$ Jeffrey P. Blount, MD, ${ }^{1}$ \\ Curtis J. Rozzelle, MD, ${ }^{1}$ James M. Johnston, MD, ${ }^{1}$ and Brandon G. Rocque, MD ${ }^{1}$
}

${ }^{1}$ Department of Neurosurgery, Division of Pediatric Neurosurgery; ${ }^{2}$ Center for Palliative and Supportive Care; ${ }^{4}$ Department of Pediatrics, University of Alabama at Birmingham; and ${ }^{3}$ Department of Biostatistics, University of Alabama at Birmingham School of Public Health, Birmingham, Alabama

OBJECTIVE Posthemorrhagic hydrocephalus of prematurity remains a significant problem in preterm infants. In the literature, there is a scarcity of data on the early disease process, when neurosurgeons are typically consulted for recommendations on treatment. Here, the authors sought to evaluate functional outcomes in premature infants at 2 years of age following treatment for posthemorrhagic hydrocephalus. Their goal was to determine the relationship between factors identifiable at the time of the initial neurosurgical consult and outcomes of patients when they are 2 years of age.

METHODS The authors performed a retrospective chart review of premature infants treated for intraventricular hemorrhage (IVH) of prematurity (grade III and IV) between 2003 and 2014. Information from three time points (birth, first neurosurgical consult, and 2 years of age) was collected on each patient. Logistic regression analysis was performed to determine the association between variables known at the time of the first neurosurgical consult and each of the outcome variables.

RESULTS One hundred thirty patients were selected for analysis. At 2 years of age, $16 \%$ of the patients had died, $88 \%$ had cerebral palsy/developmental delay (CP), 48\% were nonverbal, 55\% were nonambulatory, 33\% had epilepsy, and $41 \%$ had visual impairment. In the logistic regression analysis, IVH grade was an independent predictor of CP $(p=0.004)$, which had an estimated probability of occurrence of $74 \%$ in grade III and $96 \%$ in grade IV. Sepsis at or before the time of consult was an independent predictor of visual impairment $(p=0.024)$, which had an estimated probability of $58 \%$. IVH grade was an independent predictor of epilepsy $(p=0.026)$, which had an estimated probability of $18 \%$ in grade III and $43 \%$ in grade IV. The IVH grade was also an independent predictor of verbal function $(p=0.007)$, which had an estimated probability of $68 \%$ in grade III versus $41 \%$ in grade IV. A higher weeks gestational age (WGA) at birth was an independent predictor of the ability to ambulate $(p=0.0014)$, which had an estimated probability of $15 \%$ at 22 WGA and up to $98 \%$ at 36 WGA. The need for oscillating ventilation at consult was an independent predictor of death before 2 years of age $(p=0.001)$, which had an estimated probability of $42 \%$ in patients needing oscillating ventilation versus $13 \%$ in those who did not.

CONCLUSIONS IVH grade was consistently an independent predictor of functional outcomes at 2 years. Gestational age at birth, sepsis, and the need for oscillating ventilation may also predict worse functional outcomes.

https://thejns.org/doi/abs/10.3171/2019.12.PEDS19381

KEYWORDS post-hemorrhagic hydrocephalus; ventriculosubgaleal shunt; functional outcomes; prematurity

I NTRAVENTRICULAR hemorrhage (IVH) and germinal matrix hemorrhage (GMH) are well-recognized complications of premature birth, affecting $10 \%-20 \%$ of infants born preterm. ${ }^{14,26} \mathrm{GMH}$ is classified as grade I-IV, as originally defined by Papile et al. and later refined by
Volpe, with the severe grade (III or IV) defined as IVH with ventricular dilation (grade III) or IVH with concomitant intraparenchymal hemorrhage (grade IV). ${ }^{13,27}$ IVH rates have been reported to be as high as $36 \%$ in extremely premature and very low birth weight infants, with severe

ABBREVIATIONS CP = cerebral palsy; CSF = cerebrospinal fluid; ELBW = extremely low birth weight; G-tube = gastrostomy tube; GA = gestational age; GMH = germinal matrix hemorrhage; $\mathrm{HC}=$ head circumference; $\mathrm{IVH}=$ intraventricular hemorrhage; $\mathrm{MV}=$ mechanical ventilation; $\mathrm{OV}=\mathrm{oscillating}$ ventilator; $\mathrm{PHH}=$ posthemorrhagic hydrocephalus; VSGS = ventriculosubgaleal shunt; WGA = weeks gestational age.

SUBMITTED June 27, 2019. ACCEPTED December 11, 2019.

INCLUDE WHEN CITING Published online February 14, 2020; DOI: 10.3171/2019.12.PEDS19381. 
grade IVH occurring in up to $16 \% .{ }^{21}$ Mortality rates can range from as low as $2 \%$ for grade I patients to as high as $60 \%$ for grade IV patients..$^{14,26}$ Infants with high-grade GMH can develop posthemorrhagic hydrocephalus (PHH) in $25 \%-74 \%$ of cases, with up to $15 \%$ eventually requiring cerebrospinal fluid (CSF) diversion for treatment. ${ }^{27}$

Functional and neurocognitive outcomes in patients treated for PHH have been defined, $, 1,6,17$ but many of the factors related to long-term functional outcome, such as the plethora of medical issues that can arise during a prolonged neonatal intensive care stay, may not be known early in the disease process. Neurosurgeons and other healthcare providers are nevertheless tasked with making decisions about these patients and counseling family members, despite a lack of information about the full disease course. Hence, it is important to have an understanding of whether data available at the time of initial consultation can give reliable information about outcomes. Equipped with this information, pediatric neurosurgeons and other healthcare providers can inform families regarding prognosis, reasonable expectations, and goals of care for their child. Thus, the primary objective of this study was to determine which factors known at the time of the initial neurosurgical consult would predict mortality and functional outcomes when the patient is 2 years of age.

\section{Methods}

\section{Cohort Selection and Data Collection}

We performed a retrospective chart review of all neonates born prematurely and treated for IVH of prematurity at Children's Hospital of Alabama between 2003 and 2014. Institutional review board (IRB) approval was obtained for this study, and informed consent was waived with IRB approval given the retrospective nature of the study. Inclusion criteria consisted of premature birth $(<37$ weeks gestational age [WGA]), grade III or IV IVH based on the Volpe classification, ${ }^{27}$ and treatment of PHH with a surgical procedure (ventriculosubgaleal shunt [VSGS], ventriculoperitoneal shunt, or endoscopic third ventriculostomy; Table 1). Exclusion criteria consisted of birth $\geq$ 37 WGA, IVH not consistent with a GMH of prematurity, premature IVH grade I or II, and premature IVH grades III and IV that did not require treatment. All patients requiring temporary CSF diversion underwent ventriculosubgaleal shunting via a technique that has been described elsewhere. ${ }^{23}$ Patients were initially identified from our database based on surgical procedure codes. After the initial screening process, those patients who fit the inclusion criteria minus those who fit the exclusion criteria were analyzed. Information was collected on each patient via retrospective chart review for three distinct time points: birth, time of first neurosurgical consult, and 2 years of age (counting from birth, unadjusted).

Predictor variables assessed at the time of birth or initial neurosurgical consultation included IVH grade (based on radiologist reports of cranial imaging), gestational age (GA) at birth (weeks), age at the time of neurosurgical consult (in weeks postconception, i.e., GA at birth plus chronological age since birth), chronological age (time from birth to neurosurgical consult), birth weight, weight at the
TABLE 1. Study eligibility criteria

\begin{tabular}{lc}
\hline \multicolumn{1}{c}{ Inclusion Criteria } & Exclusion Criteria \\
\hline $\begin{array}{l}\text { Premature birth, i.e., }<37 \text { com- } \\
\text { pleted WGA }\end{array}$ & Birth $\geq 37$ completed WGA \\
\hline Grade III or IV IVH & $\begin{array}{c}\text { IVH not consistent w/ a GMH of } \\
\text { prematurity }\end{array}$ \\
\hline $\begin{array}{l}\text { Need for treatment of PHH w/ a } \\
\text { VSGS }\end{array}$ & Premature IVH grade I or II \\
\hline & $\begin{array}{c}\text { Premature IVH grades III \& IV that } \\
\text { did not require treatment }\end{array}$ \\
\hline
\end{tabular}

time of neurosurgical consultation, need for mechanical or oscillating ventilation, head circumference (HC), history of sepsis, and history of meningitis. Functional outcomes were assessed at 2 years of age (chronological), including death before 2 years of age, cerebral palsy (CP) or developmental delay, verbal function, ability to ambulate, visual impairment, deafness, history of tracheostomy placement, history of gastrostomy tube (G-tube) placement, and epilepsy. A patient was considered to be nonambulatory if they could not ambulate at all, even with assist devices. Verbal function, visual function, and hearing were defined as dichotomous variables, with any functionality in each meriting a full assignment. Any clinical documentation of $\mathrm{CP} /$ developmental delay was considered to indicate the presence of the disorder, which was not graded by severity. This diagnosis was primarily made by pediatric rehabilitation medicine providers using standard criteria. ${ }^{16}$ Outcomes were determined using the clinical documentation at 2 years of age including neonatology, physical therapy, audiology, neurosurgery, and other medical specialist notes and documents regarding patient functionality. Data were missing for some variables at 2 years, and this is noted in the results where applicable. Data abstraction was performed by multiple authors (S.G.M., N.M.B.L., B.N.D., E.N.A.), with about $50 \%$ of the charts reviewed by two abstractors to ensure data quality.

\section{Data Analyses}

We summarize the data using means, medians, standard deviations, and quartiles for continuous variables and counts and frequencies for categorical variables. To examine the association between variables known at the time of the first consult and each of the functional outcome variables, logistic regression analyses were performed. Given the large number of predictor variables relative to the sample size, it was necessary for us to first obtain an initial set of predictors to be included in the modeling. To determine which predictors would be included in the full logistic model, association between each outcome and predictor variable was analyzed using Fisher's exact test (for categorical predictors) and the Kruskal-Wallis test (for continuous predictors). Predictors found to be significantly associated with an outcome were included in the full logistic model. We then applied a stepwise variable selection method to arrive at the final set of predictor variables. The final logistic model for each outcome was used to calculate the estimated probability (risk) of occurrence 
TABLE 2. Baseline characteristics of neonates with severe IVH at birth

\begin{tabular}{|c|c|c|c|}
\hline Characteristic & Grade III IVH $(n=53)$ & Grade IV IVH $(\mathrm{n}=77)$ & p Value* \\
\hline Birth weight, no. (\%)† & & & $<0.0001$ \\
\hline Low & $4(8.5)$ & $3(4.1)$ & \\
\hline Very low & $12(25.5)$ & $10(13.5)$ & \\
\hline Extremely low & $31(66.0)$ & $61(82.4)$ & \\
\hline Mean WGA at birth (range) $\ddagger \S$ & $26.3 \pm 2.5(22-32)$ & $25.6 \pm 2.4(22-36)$ & 0.128 \\
\hline Patients born $\leq 29$ WGA (\%)‡ & $47(90.4)$ & $72(94.7)$ & \\
\hline Sex, no. $(\%)$ & & & 0.338 \\
\hline Female & $30(56.6)$ & $36(46.8)$ & \\
\hline Male & $23(43.3)$ & $41(53.2)$ & \\
\hline Race/ethnicity, no. (\%) & & & 0.376 \\
\hline White & $23(43.4)$ & $31(40.2)$ & \\
\hline Black & $28(52.8)$ & 37 (48.1) & \\
\hline Hispanic/Latino & $2(3.8)$ & $6(7.8)$ & \\
\hline Unspecified/other & 0 & $3(3.9)$ & \\
\hline Insurance, no. (\%) & & & 0.143 \\
\hline Public & $39(73.6)$ & $56(72.7)$ & \\
\hline Private & $13(24.5)$ & $21(27.3)$ & \\
\hline Out of pocket & $1(1.9)$ & 0 & \\
\hline \multicolumn{4}{|c|}{$\begin{array}{l}n=\text { number of patients. } \\
\text { * Statistical analysis was performed using the 2-tailed Student t-test, Fisher's exact test, and chi-square test, as appropriate. Boldface type } \\
\text { indicates statistical significance. } \\
\dagger \text { Data missing in some patients: } n=47 \text { for grade III IVH, } n=74 \text { for grade IV IVH. Low: }<2500 \mathrm{~g} \text {, very low: }<1500 \mathrm{~g} \text {, extremely low: }<1000 \mathrm{~g} \\
\text { † Data missing in some patients: } n=52 \text { for grade IIII IVH, } n=76 \text { for grade IV IVH. } \\
\text { § Values reported as mean } \pm \text { standard deviation. }\end{array}$} \\
\hline
\end{tabular}

for each of the functional outcomes in question with a $95 \%$ confidence interval. All $\mathrm{p}$ values $<0.05$ were deemed significant. Data analysis was performed by a biostatistician (I.B.A.) using SAS version 9.4.

\section{Results}

\section{Cohort Demographics and Birth Variables}

One hundred thirty patients were selected for analysis. Six (4.6\%) of 130 patients were lost to follow-up prior to 2 years of age, and 20/124 (16\%) died prior to 2 years old. Sixty-six (51\%) of 130 patients were female, 54/130 (42\%) were white, and 95/130 (73\%) had public insurance (Medicaid; Table 2). Fifty-three (41\%) of 130 had grade III hemorrhage, while 77/130 (59\%) had grade IV hemorrhage. One hundred fourteen (94\%) of 121 patients were extremely low birth weight (ELBW) or very low birth weight. The mean birth weight was $0.9 \pm 0.35 \mathrm{~kg}$, while the mean GA at birth was $26 \pm 2$ weeks (range 22-36 weeks). Ninety-three percent of patients were born at a $\mathrm{GA} \leq 29$ weeks.

\section{Characteristics at the Time of First Neurosurgical Consult}

The median chronological age at consult was 30 days (range 6-114 days), and mean GA at consult was $31 \pm 3$ weeks (range 23-39 weeks; Table 3). The mean HC was $28.8 \pm 3.7 \mathrm{~cm}$, and 31/112 (28\%) patients had an $\mathrm{HC} \geq$ 90th percentile at the time of initial consult. Seventy-nine (66\%) of 119 patients were on mechanical ventilation (MV), 19/119 (16\%) were on an oscillating ventilator (OV), $42 / 120(35 \%)$ had developed sepsis (either prior to or at the time of consult), 27/119 (23\%) had necrotizing enterocolitis, 21/119 (18\%) had a cardiac anomaly, and 5/121 (4\%) had meningitis.

\section{Functional Outcomes at 2 Years of Age}

Overall, 86/98 patients (88\%) had CP or developmental delay, 45/94 (48\%) were nonverbal, 52/94 (55\%) were nonambulatory, 22/94 (23\%) ambulated without any assist devices, 5/95 (5\%) had a tracheostomy, 23/97 (24\%) had a G-tube, 32/97 (33\%) had epilepsy, 8/93 (9\%) were deaf, $36 / 88$ (41\%) had visual impairment, and 20/124 (16\%) died before the age of 2 years. Overall functional outcomes in the cohort are noted in Fig. 1, and a breakdown by IVH grade is noted in Fig. 2. Many patients exhibited multiple

TABLE 3. Characteristics at the time of the initial neurosurgical consult

\begin{tabular}{lc}
\hline \multicolumn{1}{c}{ Variable } & Value \\
\hline Median chronological age in days (range) & $30(6-114)$ \\
\hline Mean GA in wks (range) & $31 \pm 3(23-39)$ \\
\hline $\begin{array}{l}\text { No. of patients }(n=112) \text { w/ HC } \geq 90 \text { th percen- } \\
\text { tile (\%) }\end{array}$ & $31(27.7)$ \\
\hline No. of patients $(n=119)$ w/ MV (\%) & $79(66.4)$ \\
\hline No. of patients $(n=119)$ w/ OV (\%) & $19(16.0)$ \\
\hline No. of patients $(n=120)$ w/ sepsis $(\%)$ & $42(35.0)$ \\
\hline No. of patients $(n=121)$ w/ meningitis $(\%)$ & $5(4.1)$ \\
\hline
\end{tabular}

Data were missing for some patients. 


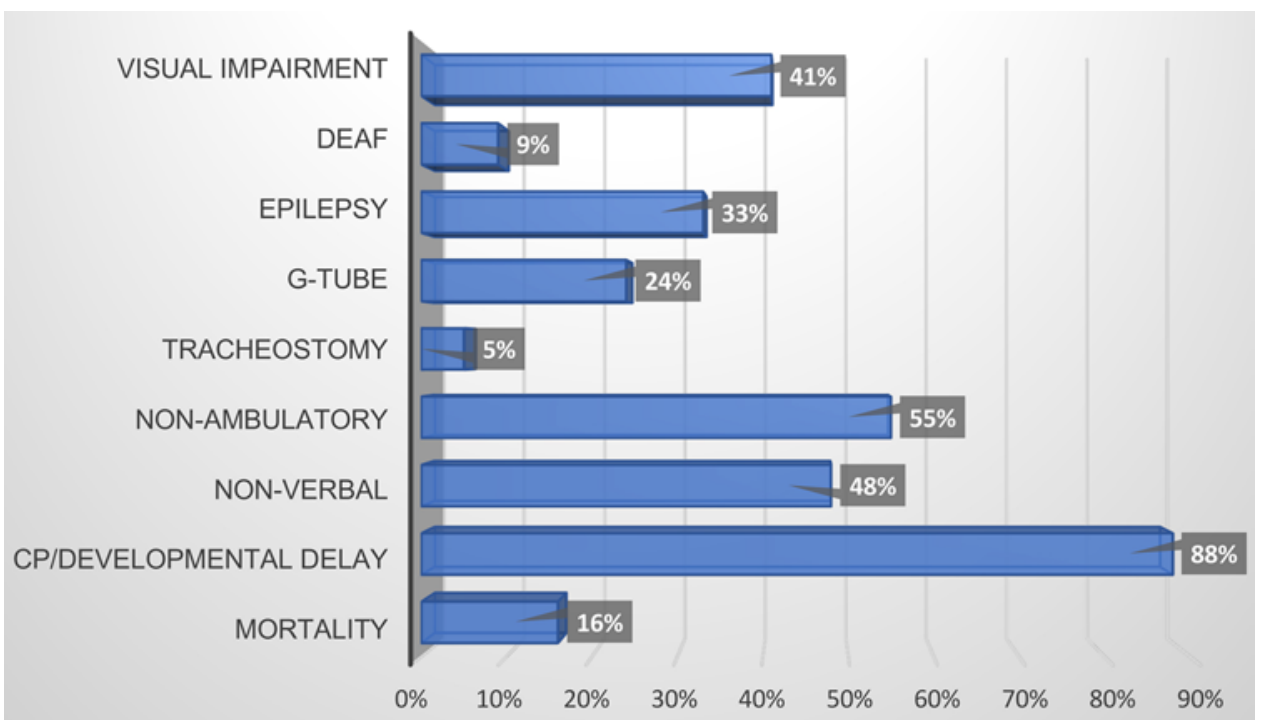

FIG. 1. Overall functional outcomes of the patient cohort at 2 years of age. The x-axis represents the percentage of patients. Figure is available in color online only.

deficits among the eight functional outcomes at 2 years of age. Note that $53.3 \%$ of the cohort had three or more deficits, while only $7.8 \%$ exhibited no deficits.

\section{Predictors of Functional Outcomes and Probability of Occurrence}

We performed initial bivariate analysis to assess for an association between each predictor variable and each functional outcome. A multivariate model was then constructed based on these results to determine the independent predictors for each outcome variable. On bivari- ate analysis, in comparing demographic/birth variables to functional outcomes at 2 years of age, we found that $\mathrm{CP} /$ developmental delay was associated with lower birth weight $(p=0.009)$ and earlier GA at birth $(p=0.017)$. The absence of ambulation was associated with public insurance $(p=0.034)$, earlier GA at birth ( $<<0.001)$, and lower birth weight $(p=0.002)$. The need for tracheostomy and epilepsy were both associated with lower birth weight $(\mathrm{p}=$ 0.03 and 0.04 , respectively).

On bivariate analysis, in testing variables at the time of neurosurgical consultation for their association with func-

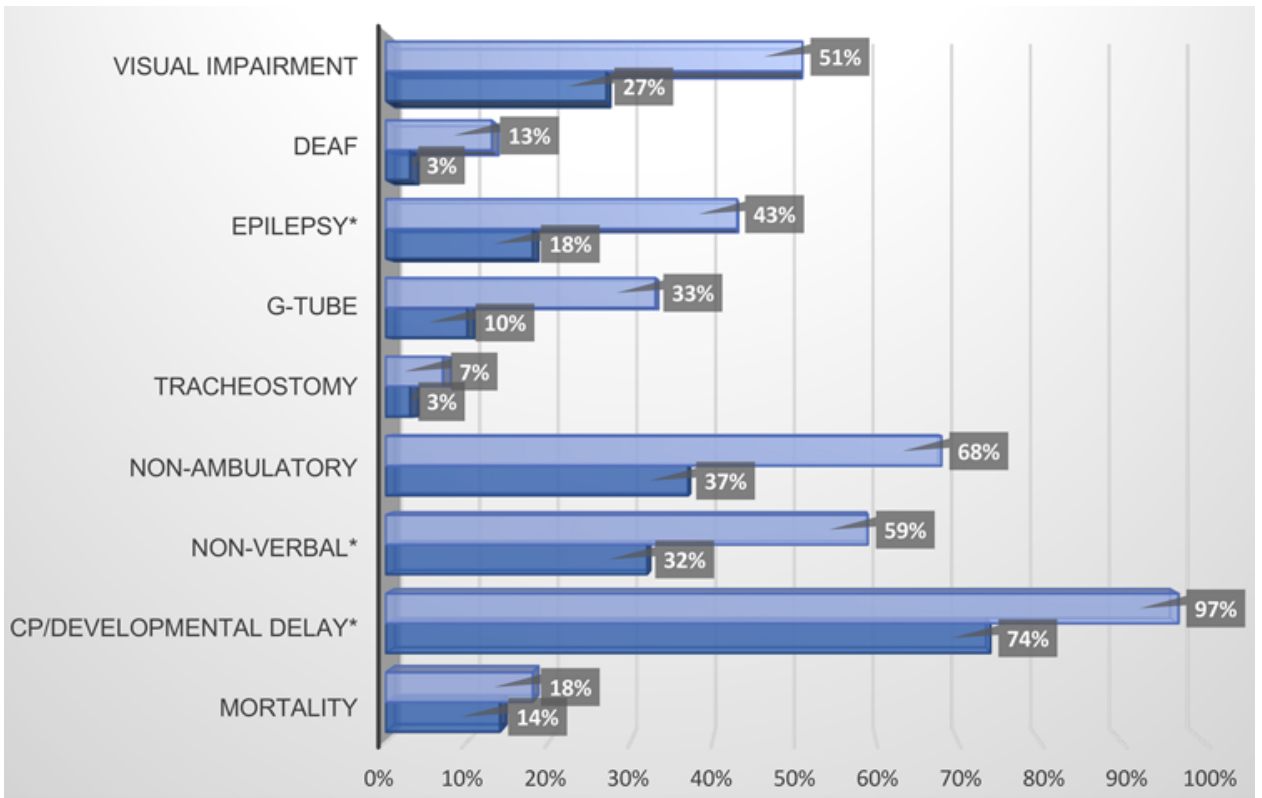

FIG. 2. Comparison of functional outcomes and mortality in grade III (dark blue bars) versus grade IV (light blue bars) IVH patients. The $x$-axis represents the percentage of patients. *Denotes IVH grade as an independent predictor of outcome. Figure is available in color online only. 
TABLE 4. Multivariate logistic regression model for select variables

\begin{tabular}{|c|c|c|c|c|}
\hline \multicolumn{2}{|l|}{ Variable } & \multirow[b]{2}{*}{$p$ Value } & \multirow[b]{2}{*}{ OR } & \multirow[b]{2}{*}{$95 \% \mathrm{Cl}$} \\
\hline Predictor & Outcome & & & \\
\hline No OV (vs OV) & Death & 0.001 & 0.142 & $0.045-0.453$ \\
\hline \multirow[t]{4}{*}{ IVH grade III (vs grade IV) } & $\mathrm{CP}$ & 0.004 & 0.075 & $0.013-0.433$ \\
\hline & Epilepsy & 0.026 & 0.325 & $0.121-0.872$ \\
\hline & G-tube & 0.013 & 0.206 & $0.059-0.716$ \\
\hline & Verbal function & 0.007 & 3.545 & $1.422-8.839$ \\
\hline Sepsis (vs no sepsis) & Normal vision & 0.024 & 0.321 & $0.12-0.86$ \\
\hline Higher WGA at birth (vs lower) & Ambulation & 0.001 & 1.532 & $1.179-1.992$ \\
\hline
\end{tabular}

Boldface type indicates statistical significance.

tional outcomes at 2 years of age, we found that $\mathrm{CP}$ was significantly associated with grade IV IVH $(p=0.0015)$, lower birth weight $(\mathrm{p}=0.02)$, and higher chronological age (i.e., time from birth to consult, $p=0.04)$. Deafness was associated with grade IV IVH $(\mathrm{p}=0.012)$ and MV $(\mathrm{p}=$ 0.048 ). The inability to ambulate was associated with IVH grade $(p=0.0035)$, the need for MV $(p=0.015)$, a lower GA at consult $(\mathrm{p}=0.006)$, and a higher HC at consult ( $p$ $=0.01)$. Epilepsy was associated with grade IV IVH $(\mathrm{p}=$ $0.015)$ and meningitis $(\mathrm{p}=0.03)$. Blindness was associated with grade IV IVH $(p=0.03)$ and sepsis $(p=0.03)$. The need for tracheostomy was associated with a lower GA at consult $(\mathrm{p}=0.0196)$ and an increased HC at consult $(\mathrm{p}=$ 0.046).

Results from the final logistic regression model are shown in Tables 4 and 5. Of note, in the final logistic regression model, only one predictor was found to be independently significant for each outcome. For ease of interpretation, we discuss the association using probabilities instead of odds ratios. In the final logistic regression model, IVH grade was an independent predictor of CP/developmental delay at 2 years $(\mathrm{p}=0.004)$, and the estimated probability of CP in grade III IVH patients was $74 \%(95 \%$ CI 58\%-86\%) versus $96 \%$ (95\% CI 87\%-99\%) in grade IV patients. Sepsis at or prior to the time of consult was an independent predictor of visual impairment at 2 years $(\mathrm{p}=0.024)$. Sepsis at consult had an estimated probability of visual impairment of 58\% (95\% CI 38\%-76\%) versus $31 \%$ (95\% CI 21\%-44\%) in the absence of sepsis. IVH grade was an independent predictor of epilepsy at 2 years $(p=0.026)$, with an estimated occurrence probability of
$18 \%(95 \%$ CI $9 \%-33 \%)$ in grade III patients versus $43 \%$ $(95 \%$ CI $31 \%-56 \%)$ in grade IV patients. IVH grade was an independent predictor of verbal function at 2 years $(p=0.007)$, with an estimated occurrence probability of $68 \%(95 \%$ CI $52 \%-81 \%)$ in grade III patients, compared to $41 \%$ (95\% CI $29 \%-54 \%$ ) in grade IV patients. Older GA at birth was an independent predictor of the ability to ambulate at 2 years $(p=0.0014)$. Patients born at 22 WGA had a $15 \%$ estimated probability of ambulation $(95 \%$ CI $6 \%-31 \%$ ) versus a $98 \%$ probability for those born at 36 WGA (95\% CI 81\%-99\%; Fig. 3).

\section{Predictors of Mortality Prior to 2 Years of Age and Predictive Probability}

No demographic or birth variables were significantly associated with mortality. A higher $\mathrm{HC}$ percentile $(\mathrm{p}=$ $0.041)$, the need for MV ( $p=0.0096)$, the need for an OV $(p=0.0052)$, and sepsis prior to or at the time of consult were significantly associated with death before 2 years of age on bivariate analysis. However, only the need for oscillating ventilation at the time of consult remained significant as a predictor of death before 2 years of age in the multivariate model $(\mathrm{p}=0.001$; Table 4$)$. The presence of an OV had a $42 \%$ estimated probability of death $(95 \%$ CI $23 \%-64 \%)$, compared to $13 \%(95 \%$ CI $7 \%-21 \%)$ for those not on an OV.

\section{Discussion}

This study has identified predictors of functional outcomes at 2 years of age in premature infants treated surgi-

TABLE 5. Predictive model and estimated probability of outcomes

\begin{tabular}{lccr}
\hline \multicolumn{1}{c}{ Variable } & & & \\
\cline { 1 - 2 } Predictor & Outcome & Estimated Probability & \multicolumn{1}{c}{$95 \% \mathrm{Cl}$} \\
\hline OV (Y vs N) & Death & $42 \%$ (vs 13\%) & $23 \%-64 \%(7 \%-21 \%)$ \\
\hline IVH grade III (vs grade IV) & CP & $74 \%($ vs $96 \%)$ & $58 \%-86 \%(87 \%-99 \%)$ \\
\hline & Epilepsy & $18 \%($ vs $43 \%)$ & $9 \%-33 \%(31 \%-56 \%)$ \\
\hline & Verbal function & $68 \%($ vs $41 \%)$ & $52 \%-81 \%(29 \%-54 \%)$ \\
\hline Sepsis (Y vs N) & Visual impairment & $58 \%$ (vs 31\%) & $38 \%-76 \%(21 \%-44 \%)$ \\
\hline Higher WGA at birth (vs lower) & Ambulation & See Fig. 3 & \\
\hline
\end{tabular}

$\mathrm{N}=$ not present; $\mathrm{Y}=$ present. 


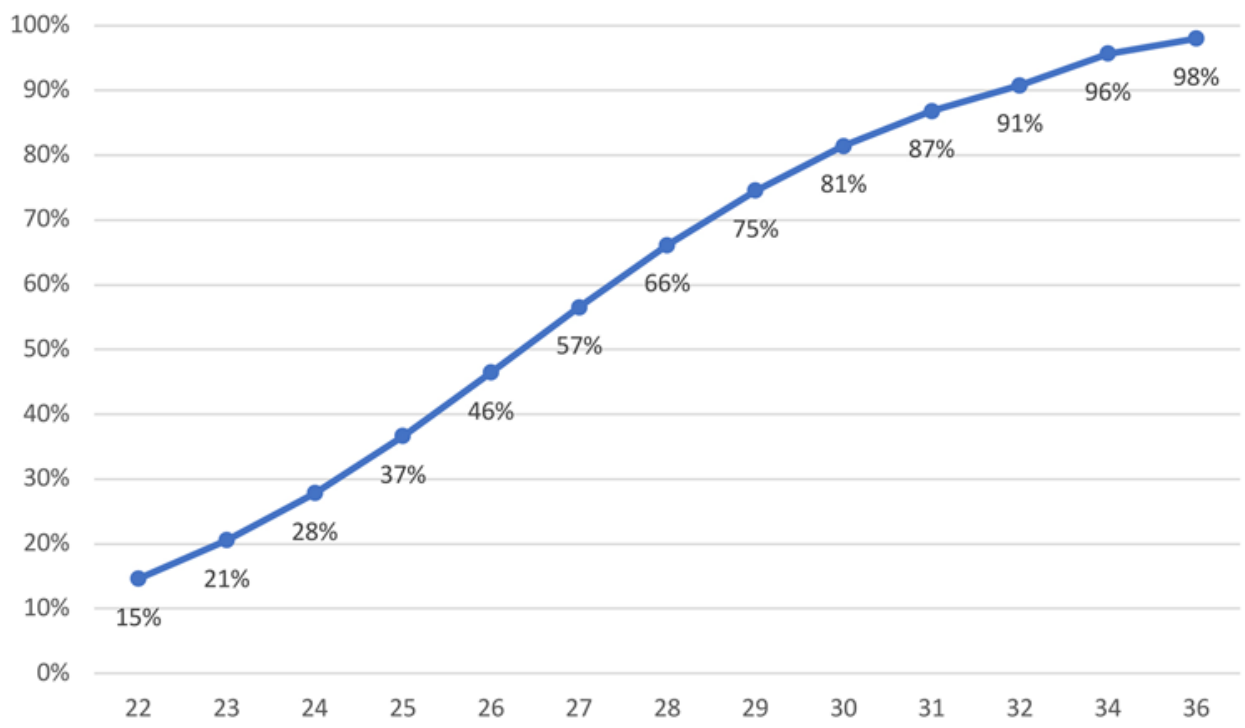

FIG. 3. Predictive model estimating the probability of ambulation at 2 years of age. The $x$-axis represents WGA at birth (unadjusted). The y-axis represents the percentage of patients. Figure is available in color online only.

cally for $\mathrm{PHH}$, with a focus on predictor variables present at the time of initial neurosurgical consultation. While several studies have addressed functional and neurocognitive outcomes in this patient population, there remains a paucity of data providing a predictive model with probabilities that can be utilized early in the disease process to guide discussions about goals of care when the neurosurgical service is initially consulted. Overall, $88 \%$ of patients in our cohort had developmental delay or $\mathrm{CP}$, and almost half of the cohort was nonverbal, nonambulatory, or blind $(48 \%, 55 \%$, and $41 \%$, respectively) by the completion of follow-up. More importantly, 16\% (20/124) of the patients died before the end of the follow-up period. These findings underscore the severity of the disease process encountered and are consistent with results in other large studies of functional outcomes in this patient population. ${ }^{10}$

\section{Case Example}

The utility of this study lies in its ability to address the percentage probability of various outcomes, a measure that is potentially useful in family discussions and more easily understandable by the lay population. With these data, percentage probabilities can be calculated at the time of initial consultation to aid in discussions on goals of care. For example, consider an infant born at 26 WGA with a grade IV IVH. The neurosurgical team is consulted at a corrected GA of 30 weeks for the management of hydrocephalus. At the time of initial consultation, the patient is on an OV but has no history of sepsis. According to the predictive model, this patient by 2 years of age has an estimated probability of $42 \%$ for death, $96 \%$ for CP/developmental delay, $43 \%$ for epilepsy, $41 \%$ for verbal function, $31 \%$ for visual impairment, and $46 \%$ for the ability to ambulate (Table 5). This information gives consultants a means of communicating effectively with patient families at a time when the current literature has not provided significant data to give an accurate representation of out- comes. Further data analyses in the future will be valuable to corroborate these results.

\section{Predictors and Functional Outcomes}

We found a significant association between birth weight class and severity of IVH grade, specifically that ELBW $(<1000 \mathrm{~g})$ was associated with a higher incidence of severe grade hemorrhage. Seventy-one percent of the overall cohort and $82 \%$ of the grade IV hemorrhages were in the ELBW class. This finding is in line with published literature reporting an incidence of severe hemorrhage between $49 \%$ and $62 \%$ in ELBW infants., ${ }^{5,22}$ Our multivariate analysis showed that IVH grade was the only independently significant predictor of CP, epilepsy, and verbal impairment. This finding is consistent with the literature, which has shown that IVH grade alone and not birth weight is a factor in neurodevelopmental outcomes. ${ }^{2,4}$

Our study revealed that grade IV (vs grade III) hemorrhage is a consistent independent predictor of a poor functional outcome at 2 years across nearly all outcome variables considered. In the logistic regression, grade III IVH at the time of initial consultation, compared with grade IV IVH, was an independent predictor of a better outcome for three variables. It was predictive of better neurocognitive and motor function (absence of CP or developmental delay), verbal function, and seizure freedom rate at 2 years of age. This finding is consistent with previous studies looking at the relationship between IVH grade and functional outcomes, with a higher-grade hemorrhage being associated with worse outcomes. ${ }^{14,26}$ A notable exception was death prior to 2 years of age, which did not show a significant correlation with IVH grade in our study but has been shown to correlate in others. ${ }^{2,14,15,20,25,26}$

The ability to ambulate demonstrated an independent association with GA at birth (Fig. 3). Ambulatory status and physical activity have been shown in recent studies to have enormous implications on quality of life in 
children with $\mathrm{CP}$, underscoring the importance of being able to predict ambulatory status early on in this patient population. ${ }^{8,12}$ We assessed ambulatory ability at 2 years' chronological age. While some premature children may improve in ambulatory ability after this time point, we suggest that the assessment of ambulation at 2 years remains valuable. In an evaluation of 95 children born at $<30$ WGA, the median time to ambulation was 15.7 months' corrected age. ${ }^{11}$ Similarly, in a study of over 800 children with birth weights less than $1500 \mathrm{~g}$, the median time to ambulation was 13 months. ${ }^{9}$ Therefore, by 24 months' chronological age, the effect of prematurity is likely less important than the effect of neurological impairment on ambulatory ability.

\section{Mortality}

In the literature, the mortality rates for patients, regardless of their IVH grade, who received a VSGS have been reported to be $9 \%$ by Tubbs et al., $12 \%$ by Sklar et al., $16 \%$ by Willis et al., and $20 \%$ by Fulmer et al. ${ }^{3,19,24,29}$ Moreover, other studies have shown higher rates of mortality based on the severity of hemorrhage: $38.5 \%$ for grade III and $50 \%$ for grade IV by Linder et al., $26 \%$ for grade III and $59 \%$ for grade IV by Vassilyadi et al., and $86 \%$ for grade III and $100 \%$ for grade IV by Kadri et al.,7,26 Vassilyadi et al. conducted a study in 284 patients, demonstrating a higher odds ratio for mortality with grade IV versus grade III in a logistic regression (OR 5.1,95\% CI 1.9-14.7, p < $0.01){ }^{26}$ While IVH severity grade has been shown to increase the mortality rate in the aforementioned studies, this finding was not reflected in the present study, where grade IV (vs grade III) was not significantly associated with a higher mortality rate (18\% vs $14 \%$, respectively). It is unclear why mortality rates were lower in the present study than in others evaluating neurodevelopmental outcomes, such as those by Vassilyadi et al. and Linder et al., but our mortality rates are similar to those occurring after

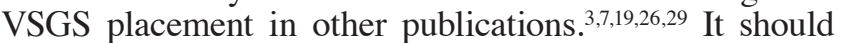
be noted that the Tubbs et al. and Fulmer et al. publications both originated from our institution, with a similar patient population; however, the mortality rates coincide with those in studies from other institutions as well. 3,19,24,29

Other factors, such as a higher HC percentile (suggesting already clinically impactful hydrocephalus), the need for $\mathrm{MV}$, the need for an $\mathrm{OV}$, and sepsis prior to or at the time of consult were also significantly associated with mortality. Both Stoll et al. and Linder et al. have noted that sepsis is associated with poor outcomes and a greater risk of high-grade IVH. ${ }^{7,21}$ Furthermore, the absence of oscillating ventilation at the time of consult was an independent predictor of survival to 2 years of age, and the presence of an OV had a $42 \%$ estimated probability of death before that time in this study. This is likely representative of these patients' overall clinical status, with high-frequency oscillatory ventilation being utilized more frequently in sicker patients.

\section{Threshold for Neurosurgical Consultation}

One of the purposes of this study was to determine what information available at the time of neurosurgical consultation is associated with functional outcomes. Because we collected information at the time of consultation, it is important to note the criteria for neurosurgical consultation at our institution. In general, neurosurgical consultation is obtained when cranial ultrasound shows ventriculomegaly. Ultrasonography is performed on a regular basis, with additional imaging performed if there are other clinical concerns for neurological impairment or if $\mathrm{HC}$ is growing rapidly. Patients included in this study were treated from 2003 to 2014 , and there may have been changes in consultation practice during that time period. However, on multivariate analysis, none of the variables at the time of consultation showed significant independent association with any of the outcomes, with the exception of oscillating ventilation (associated with mortality) and history of sepsis (associated with visual impairment). Oscillating ventilation is likely an indication of severe systemic illness; therefore, its association with mortality is not surprising. Thus, we suggest that changes in when neurosurgical consultation is sought may not have a large impact on the results of this study.

\section{Study Limitations}

As with all retrospective studies, certain limitations must be noted. We selected specific, measurable, and identifiable predictor variables and outcomes for analysis. Therefore, other risk factors not evaluated in this study may have been present and thus could confound the results. We tried to correct for this by using clear predictor and outcome variables that were chosen after literature review of other neurodevelopmental studies assessing a similar patient population. This study did not include any grading for the severity of the outcome CP or developmental delay, which would have provided useful information. This was done given the restraints of the retrospective data available to us; however, we have included other outcome variables, such as verbal and ambulatory status, to try to improve the utility of the information provided.

Because patients were identified using surgical records, only those who had undergone treatment for hydrocephalus with a VSGS were included in this study. Therefore, we cannot make any comparison to infants with lower-grade IVH or to those with grade III or IV hemorrhage who did not require surgical treatment. These data cannot guide counseling in terms of children with IVH who do not require surgical treatment. In addition, because surgical treatment was used as an inclusion criterion, the threshold for treatment must be considered. The institutional threshold for treatment of IVH did not change significantly over the study period and is similar to the protocol described in the publication "Shunting outcomes in posthemorrhagic hydrocephalus: results of a Hydrocephalus Clinical Research Network prospective cohort study."28

During the review and data extraction phase of this study, 6/130 (4.6\%) patients were lost to follow-up prior to 2 years of age and $20 / 124(16 \%)$ died prior to 2 years old. Missing data was an issue for some variables in both predictor and outcome groups. Every attempt was made to collect as much information as possible on each patient, but the limitations of retrospective data collection make it difficult to achieve completeness. Therefore, any data that were irretrievable were not included in the final analysis. This has the potential to introduce selection bias and a 
type II false-negative statistical error for certain outcomes because of underpowered sampling.

There is a risk of a type I (false-positive) statistical error given the large number of independent variables analyzed relative to the number of dependent variable outcomes. However, the creation of a logistic regression model by selecting variables based on the results of bivariate analysis inherently corrects for the problem of multiple measures to some degree.

Despite these limitations, this study may help pediatric neurosurgeons and healthcare providers identify factors associated with and predictive of death and functional outcomes at 2 years of age. These predictive models can ultimately provide an early, valuable means by which to counsel families, allowing them to make educated decisions about goals of care for their children.

\section{Conclusions}

The goal of this study was to identify factors that predict functional outcomes and death by 2 years of age in patients treated for PHH after grade III or IV IVH of prematurity. In particular, this study focused uniquely on predictors present at birth or the time of initial neurosurgical consultation, with the goal of identifying factors affecting developmental outcomes early in the disease process. Healthcare providers are routinely tasked with holding family discussions and counseling patients' families early on and throughout the disease course, but there may not be adequate data in the literature to do so accurately. In this study, grade IV (vs grade III) IVH was a consistent independent predictor of poor functional outcomes at 2 years of age, although there was no significant difference in mortality between the two grades. Surprisingly, several variables such as birth weight, WGA at birth, and medical comorbidities were either not predictive or predictive of only certain individual outcomes. Future studies to determine the impact of this information on a parent's experience in making care decisions would help illustrate the potential importance of these findings. Knowing certain factors at the time of the initial neurosurgical consult, such as IVH grade and ventilatory status, can give us meaningful prognostic clues to aid in family discussions, especially as they pertain to goals of care.

\section{Acknowledgments}

Dr. Alford completed this work as the University of Alabama at Birmingham Department of Neurosurgery Women's Leadership Council Research Scholar.

\section{References}

1. Adams-Chapman I, Hansen NI, Stoll BJ, Higgins R: Neurodevelopmental outcome of extremely low birth weight infants with posthemorrhagic hydrocephalus requiring shunt insertion. Pediatrics 121:e1167-e1177, 2008

2. Calisici E, Eras Z, Oncel MY, Oguz SS, Gokce İK, Dilmen U: Neurodevelopmental outcomes of premature infants with severe intraventricular hemorrhage. J Matern Fetal Neonatal Med 28:2115-2120, 2015

3. Fulmer BB, Grabb PA, Oakes WJ, Mapstone TB: Neonatal ventriculosubgaleal shunts. Neurosurgery 47:80-84, 2000

4. Goldstein RF, Cotten CM, Shankaran S, Gantz MG, Poole
WK: Influence of gestational age on death and neurodevelopmental outcome in premature infants with severe intracranial hemorrhage. J Perinatol 33:25-32, 2013

5. Kadri H, Mawla AA, Kazah J: The incidence, timing, and predisposing factors of germinal matrix and intraventricular hemorrhage (GMH/IVH) in preterm neonates. Childs Nerv Syst 22:1086-1090, 2006

6. Klebermass-Schrehof K, Czaba C, Olischar M, Fuiko R, Waldhoer T, Rona Z, et al: Impact of low-grade intraventricular hemorrhage on long-term neurodevelopmental outcome in preterm infants. Childs Nerv Syst 28:2085-2092, 2012

7. Linder N, Haskin O, Levit O, Klinger G, Prince T, Naor N, et al: Risk factors for intraventricular hemorrhage in very low birth weight premature infants: a retrospective case-control study. Pediatrics 111:e590-e595, 2003

8. Mann K, Tsao E, Bjornson KF: Physical activity and walking performance: Influence on quality of life in ambulatory children with cerebral palsy (CP). J Pediatr Rehabil Med 9:279-286, 2016

9. Marín Gabriel MA, Pallás Alonso CR, De La Cruz Bértolo J, Caserío Carbonero S, López Maestro M, Moral Pumarega $\mathrm{M}$, et al: Age of sitting unsupported and independent walking in very low birth weight preterm infants with normal motor development at 2 years. Acta Paediatr 98:1815-1821, 2009

10. Mukerji A, Shah V, Shah PS: Periventricular/intraventricular hemorrhage and neurodevelopmental outcomes: a meta-analysis. Pediatrics 136:1132-1143, 2015

11. Nuysink J, van Haastert IC, Eijsermans MJC, KoopmanEsseboom C, Helders PJM, de Vries LS, et al: Prediction of gross motor development and independent walking in infants born very preterm using the Test of Infant Motor Performance and the Alberta Infant Motor Scale. Early Hum Dev 89:693-697, 2013

12. Omura J, Fuentes M, Bjornson K: Participation in daily life: influence on quality of life in ambulatory children with cerebral palsy. PM R 10:1185-1191, 2018

13. Papile LA, Burstein J, Burstein R, Koffler H: Incidence and evolution of subependymal and intraventricular hemorrhage: a study of infants with birth weights less than 1,500 gm. J Pediatr 92:529-534, 1978

14. Radic JAE, Vincer M, McNeely PD: Outcomes of intraventricular hemorrhage and posthemorrhagic hydrocephalus in a population-based cohort of very preterm infants born to residents of Nova Scotia from 1993 to 2010. J Neurosurg Pediatr 15:580-588, 2015

15. Resch B, Gedermann A, Maurer U, Ritschl E, Müller W: Neurodevelopmental outcome of hydrocephalus following intra-/periventricular hemorrhage in preterm infants: shortand long-term results. Childs Nerv Syst 12:27-33, 1996

16. Richards CL, Malouin F: Cerebral palsy: definition, assessment and rehabilitation. Handb Clin Neurol 111:183-195, 2013

17. Roze E, Van Braeckel KNJA, van der Veere CN, Maathuis CGB, Martijn A, Bos AF: Functional outcome at school age of preterm infants with periventricular hemorrhagic infarction. Pediatrics 123:1493-1500, 2009

18. Schellinger D, Grant EG, Manz HJ, Patronas NJ: Intraparenchymal hemorrhage in preterm neonates: a broadening spectrum. AJR Am J Roentgenol 150:1109-1115, 1988

19. Sklar F, Adegbite A, Shapiro K, Miller K: Ventriculosubgaleal shunts: management of posthemorrhagic hydrocephalus in premature infants. Pediatr Neurosurg 18:263-265, 1992

20. Srinivasakumar P, Limbrick D, Munro R, Mercer D, Rao R, Inder T, et al: Posthemorrhagic ventricular dilatation-impact on early neurodevelopmental outcome. Am J Perinatol 30:207-214, 2013

21. Stoll BJ, Hansen NI, Bell EF, Shankaran S, Laptook AR, Walsh MC, et al: Neonatal outcomes of extremely preterm 
infants from the NICHD Neonatal Research Network. Pediatrics 126: $443-456,2010$

22. Trounce JQ, Rutter N, Levene MI: Periventricular leucomalacia and intraventricular haemorrhage in the preterm neonate. Arch Dis Child 61:1196-1202, 1986

23. Tubbs RS, Banks JT, Soleau S, Smyth MD, Wellons JC III, Blount JP, et al: Complications of ventriculosubgaleal shunts in infants and children. Childs Nerv Syst 21:48-51, 2005

24. Tubbs RS, Smyth MD, Wellons JC III, Blount J, Grabb PA, Oakes WJ: Life expectancy of ventriculosubgaleal shunt revisions. Pediatr Neurosurg 38:244-246, 2003

25. van Zanten SA, de Haan TR, Ursum J, van Sonderen L: Neurodevelopmental outcome of post-hemorrhagic ventricular dilatation at 12 and 24 months corrected age with highthreshold therapy. Eur J Paediatr Neurol 15:487-492, 2011

26. Vassilyadi M, Tataryn Z, Shamji MF, Ventureyra ECG: Functional outcomes among premature infants with intraventricular hemorrhage. Pediatr Neurosurg 45:247-255, 2009

27. Volpe J: Intracranial hemorrhage: germinal matrix-intraventricular hemorrhage, in Neurology of the Newborn, ed 5. Philadelphia: Saunders Elsevier, 2008, pp 517-588

28. Wellons JC III, Shannon CN, Holubkov R, Riva-Cambrin J, Kulkarni AV, Limbrick DD Jr, et al: Shunting outcomes in posthemorrhagic hydrocephalus: results of a Hydrocephalus Clinical Research Network prospective cohort study. J Neurosurg Pediatr 20:19-29, 2017

29. Willis BK, Kumar CR, Wylen EL, Nanda A: Ventriculosubgaleal shunts for posthemorrhagic hydrocephalus in premature infants. Pediatr Neurosurg 41:178-185, 2005

\section{Disclosures}

The authors report no conflict of interest concerning the materials or methods used in this study or the findings specified in this paper.

\section{Author Contributions}

Conception and design: Rocque, McClugage, Arynchyna, Peralta-Carcelen, Blount, Rozzelle, Johnston. Acquisition of data: McClugage, Laskay, Donahue, Arynchyna, Zimmerman, Alford. Analysis and interpretation of data: all authors. Drafting the article: McClugage, Laskay, Zimmerman, Aban. Critically revising the article: all authors. Reviewed submitted version of manuscript: all authors. Approved the final version of the manuscript on behalf of all authors: Rocque. Statistical analysis: Rocque, McClugage, Arynchyna, Aban. Administrative/technical/ material support: Rocque, Donahue, Arynchyna, Zimmerman, Aban, Alford, Peralta-Carcelen, Blount, Rozzelle, Johnston. Study supervision: Rocque, Arynchyna, Peralta-Carcelen, Blount, Rozzelle, Johnston.

\section{Supplemental Information \\ Previous Presentations}

Portions of this paper in a poster presentation format and an abstract related to the data discussed in this paper were previously presented at the annual meeting of the AANS/CNS Section on Pediatric Neurological Surgery held in Houston, Texas, on November 30, 2017.

\section{Correspondence}

Brandon G. Rocque: University of Alabama at Birmingham, AL. brandon.rocque@childrensal.org. 